\title{
MECHANISM OF INITIATION OF POLYMERIZATION BY FERRIC ACETYLACETONATE
}

Results on the autooxidative decomposition of the transition metal B-diketonates (1-3) suggested the possibility of these chelates acting as initiators for the radical polymerization of vinyl monomers. Research in this field soon revealed the importance of the central metal atom as well as the ligand structure (4-10). Of a series of metal acetylacetonates-Mn(Acac $)_{2}, \mathrm{Mn}(\mathrm{Acac})_{3}, \mathrm{Fe}$ $(\mathrm{Acac})_{3}, \mathrm{Co}(\mathrm{Acac})_{2}, \mathrm{Ni}(\mathrm{Acac})_{2}$ etc. $-\mathrm{Mn}(\mathrm{Acac})_{3}$ was found to be the most effective initiator; its efficiency was comparable to that of tertiary butyl hydroperoxide. The striking influence of the ligand in determining the activity of the chelate was brought about through the studies carried out by Bamford et al. (7) on $\mathrm{Mn}(\mathrm{Acac})_{3}, \mathrm{Mn}\left(\mathrm{p}-\mathrm{p}^{\prime} \text { dichloro } \mathrm{DBM}\right)_{3}, \mathrm{Mn}(\mathrm{FAcac})_{3}$, and $\mathrm{Mn}$ $(\mathrm{DBM})_{3}$.

A monomer order of higher than unity is a widely observed and naturally accepted feature of the chelate-initiated polymerization systems. The order with respect to the chelate is almost always close to 0.5. Bamford suggested, in agreement with Arnett and Mendelsohn (1-3), that the initial initiation step involves the scission of the ligand as a free radical and the reduction of the metal as in the following equation:

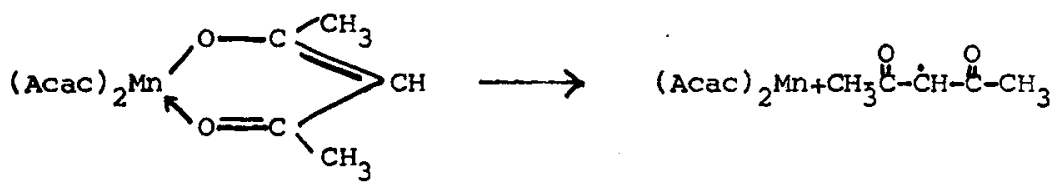

But he feels that the process is probably more complicated than that represented by the equation, and that monomer may be involved in the initiation process, since the order with respect to the monomer for the overall polymerization reaction exceeds unity. For methyl methacrylate in benzene and styrene in toluene, the order is close to 1.5 .

Uehara et al. (10) have observed that the 3-substituted copper(II) acetylacetonates are good initiators. These chelates are stable when heated in benzene alone, in the absence of the monomer; but in the presence of styrene, decomposition and subsequent polymerization occur. Naturally a monomer order of 1.8 was observed. These investigators suggested an initiation mechanism involving an interaction between the chelate and the monomer.

Experiments carried out in this laboratory using $\mathrm{Fe}(\mathrm{DPM})_{3}$ and $\mathrm{Fe}(\mathrm{Acac})_{3}$ provide conclusive evidence for the involvement of the monomer in the initiation step of the polymerization reaction.

The inhibitory effects of hydroquinone and DPPH in the polymerizations of methyl methacrylate and styrene using the above initiators indicated a free- 


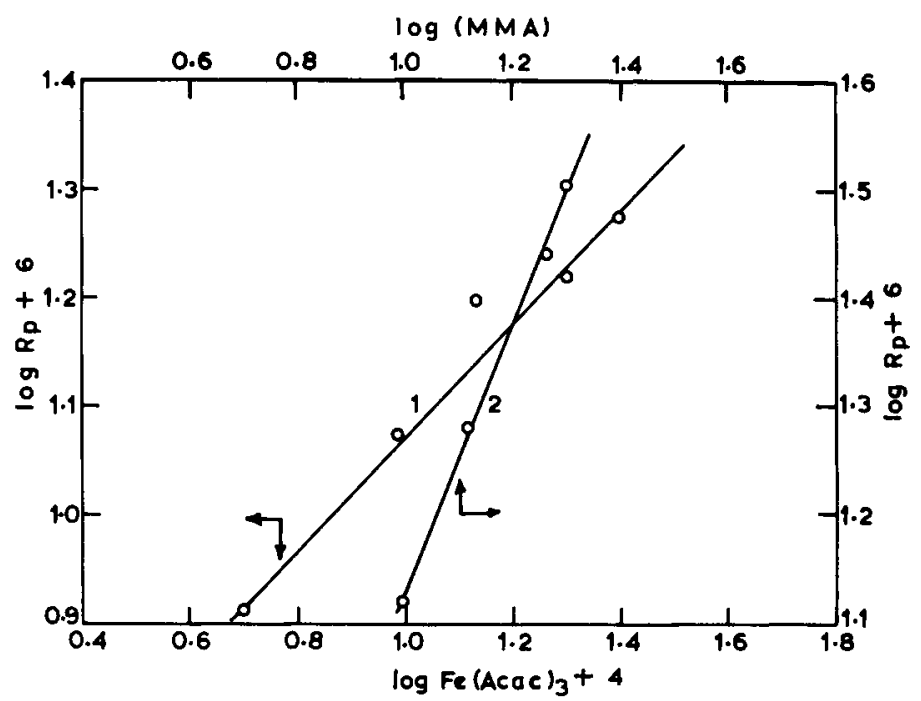

Fig. 1. (1) Effect of $\mathrm{Fe}(\mathrm{Acac})_{3}$ on the rate of polymerization of MMA at $70^{\circ} \mathrm{C}$ in benzene. [MMA] $=4.7 \mathrm{~mole} / 1$. (2) Effect of MMA concentration on the rate of polymerization in the presence of $\mathrm{Fe}(\mathrm{Acac})_{3}$ at $70^{\circ} \mathrm{C}$ in benzene.

radical mechanism. The values of $\delta$ and $\mathrm{C}_{M}$ obtained with ferric acetylacetonate-initiated systems for styrene and methyl methacrylate, are in good agreement with those reported in the literature for conventional free-radical systems. The square-root dependency of the rate of polymerization on the chelate concentration suggests bimolecular termination reaction. The monomer order in $\mathrm{Fe}(\mathrm{Acac})_{3}$ is close to 1.5. (Fig. 1).

Even though Arnett et al. (1-3) have suggested that direct decomposition of ferric acetylacetonate, such as,

$\mathrm{Fe}(\mathrm{Acac})_{3} \longrightarrow \mathrm{Fe}(\mathrm{Acac})_{2}+\mathrm{Acac}$

is possible, this seems to be improbable in the absence of oxygen. According to Vanhoene et al. (11), ferric acetylacetonate does not undergo low-temperature thermal decomposition. If it decomposes at all, the decomposition sets in at somewhere near its melting point $\left(164^{\circ} \mathrm{C}\right)$. All the polymerization experiments are carried out at temperatures below $80^{\circ} \mathrm{C}$ and obviously it is difficult to assume direct decomposition of the chelate to be solely responsible for the radical production.

This convincingly rules out the direct decomposition of the ferric chelate to be a radical-producing reaction. The proof for the monomer-chelate interaction was obtained from spectroscopic investigations. Ferric acetylacetonate exhibits a strong absorption peak in the ultraviolet region at $278 \mathrm{~nm}$. This peak appears unchanged in solvents like benzene, chloroform, alcohol, etc., 


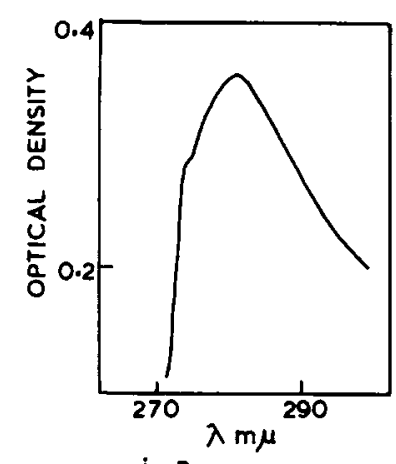

in Benzene

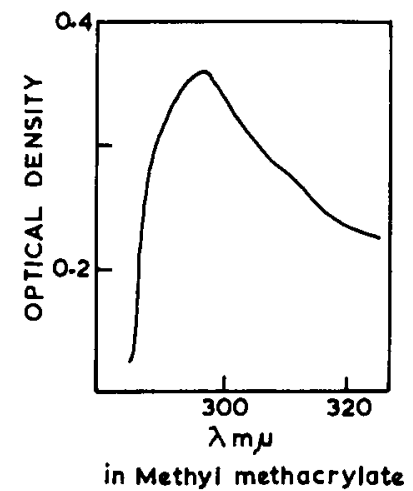

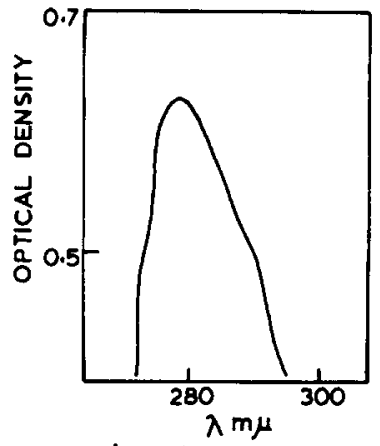

in Chloroform

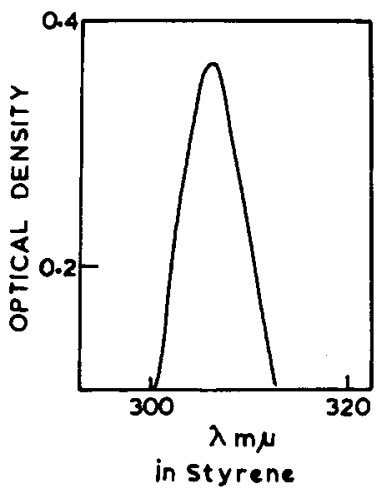

Fig. 2. Spectra of ferric Acac in different solvents at room temperature. Concentration of the chelate $\sim 10^{-5} \mathrm{M}$.

and has been assigned to the II $\longrightarrow$ II* transition, characteristic of the coordinated ligand (12). When styrene or methyl methacrylate is employed as the solvent, this peak shifts to $308 \mathrm{~nm}$ or $298 \mathrm{~nm}$, respectively. Hence it may be assumed that the interaction between the chelate and the monomer greatly affects the ligand part and promotes the induced decomposition of the chelate to yield radicals. The decomposition may be envisaged as:

$$
\mathrm{Fe}(\mathrm{Acac})_{3}+\text { Monomer } \longrightarrow[\text { Complex }] \longrightarrow \mathrm{Fe}(\text { Acac })_{2}+\mathrm{R}^{\cdot}
$$

This is quite consistent with the detection of ferrous in the reaction mixture.

The interaction between the chelate and the monomer is found to occur only in solution and the Job's variation method as well as the Benesi-Hildeband plot shows the stoichiometry of interaction to be $1: 1$. 


\section{References}

(1) M. Mendelsohn, E. M. Arnett, and H. Freiser, J. Phys. Chem., 64, 660 (1960).

(2) E. M. Arnett and M. Mendelsohn, J. Amer. Chem. Soc., 84, 3821 (1962).

(3) E. M. Arnett, H. Freiser, and M. Mendelsohn, J. Amer. Chem. Soc., 84, 2482 (1962).

(4) E. G. Kastning, H. Naarman, H. Reis, and C. Berding, Angew. Chem., $\underline{4}, 322$ (1965).

(5) C. H. Bamford and D. J. Lind, Chem. Commun., 792 (1966).

(6) C. H. Bamford and D. J. Lind, Proc. Roy. Soc., A302, 145 (1967).

(7) C. H. Bamford and D. J. Lind, Chem. Ind. London, 1627 (1965).

(8) C. H. Bamford, Macromol. Chem., Int. Symp. Tokyo \& Kyoto) $\underline{3}$, 333 (1966).

(9) T. Otsu, N. Minamii, and Y. Nishikawa, J. Macromol. Sci. Chem., 2(5), 902 (1968).

(10) K. Uehara, T. Matsumara, Y. Murata, M. Tanaka, and J. Murata, Chem. Abstr., 72, 32349v (1970).

(11) J. Vanhoene, G. Charles, and W. M. Hickam, J. Phys. Chem., 62, 1098 (1958).

(12) D. W. Barnum, J. Inorg. Nucl. Chem., 21, 221 (1961); 22, 183 (1961).

R. Prabha

U. S. Nandi

Dept. of Inorganic and Physical Chemistry

Indian Institute of Science

Bangalore, India 560012

Received October 1, 1975 